\title{
Temporary Immunity of Blackbelly Lambs Reinfected with Trichostrongylus colubriformis
}

\author{
Roberto González Garduño', María Eugenia López Arellano², Pedro Mendoza de Gives², \\ Nadia Florencia Ojeda Robertos ${ }^{3} \&$ Alfonso Juventino Chay Canul ${ }^{3}$
}

\begin{abstract}
Background: Trichostrongylus colubriformis is one of the most prevalent gastrointestinal nematodes of sheep in warm climates. In this nematode species, anthelmintic resistance (AR) has been reported, which has motivated the search for alternative methods to control it. One practice is to increase the immune response level through the selection of animals with natural resistance, such as Blackbelly sheep. The aim of this study was to investigate the response of $\operatorname{IgA}$ and $\operatorname{IgG}$ in serum and saliva and the level of cells involved in the acquired resistance in Blackbelly lambs after single artificial reinfection with a resistant strain of Trichostrongylus colubriformis.

Materials, Methods \& Results: Sixteen weaned lambs grazed for one month in nematode-contaminated grasslands. All the lambs were treated with Albendazole and Levamisole; later, they were stabled for two months. After that, eight lambs were re-infected with 6000 larvae of $T$. colubriformis and other eight lambs remained naturally infected. In addition, eight nematode-free lambs raised in cages, served as negative control. Blood samples were taken fortnightly to determine packed cell volume (PCV, \%), plasmatic protein $\left(\mathrm{g} \mathrm{dL}^{-1}\right)$, as well as absolute and differential leukocytes. The eggs per gram of feces (EPG) were recorded. An indirect ELISA against T. colubriformis Ag was performed to determine the IgG and IgA levels. All data were analyzed by repeated measures. The EPG in the re-infected group increased after 34 days $(625 \pm 287)$, while in the naturally infected group it remained close to $200 \pm 158$ throughout the study. The control lambs did not show any infection. The PCV $(29.4 \pm 3.4 \%)$, basophils $(44 \pm 74)$, lymphocytes $(8443 \pm 2845)$ and monocytes $(77 \pm 91)$ counts were not affected by infection. The IgA OD against $T$. colubriformis increased significantly after 15 days post-infection (dpi) in the re-infected lambs $(1.69 \pm 0.5,80 \%$ with regards to standard). With IgG was not possible to distinguish the effect of infection.

Discussion: Highly persistent infection of T. colubriformis was observed for at least four months in the naturally infected group despite having been treated with anthelmintics. It is a significant problem because this species has a high prevalence in the region of study and shows anthelmintic resistance. For such reason, is important to evaluate the ability of the animal to develop an immune response. In other study, a natural reduction in the fecal egg count (FEC) was indicated at $100 \mathrm{dpi}$ in the same species, but in the present work, the FEC could not be reduced until around 120 days when the naturally infected lambs were evaluated. The larger number of neutrophils and leukocytes in both the naturally infected and re-infected groups implies a sustained response for a long time. While the higher counts of eosinophils only in the re-infected group were produced as an immediate response to infection with T. colubriformis. Similarly, with a single infection of T. colubriformis, in Santa Ines sheep the infected lambs showed significantly higher levels of serum IgA than the control group. In this case, differences in IgA activity were observed between the re-infected lambs and the other groups at fifteen dpi, but the basal levels of IgA in the naturally pre-infected lambs were maintained at least five weeks after infection. In conclusion, an increase in the peripheral immune response in lambs re-infected with T. colubriformis resulted from the increase in IgA levels in serum and saliva, and increase in the number of peripheral eosinophils, total leukocytes and neutrophils. Re-infected lambs had a higher level of IgA than naturally infected lambs and control lambs, making possible to promote the immune response with a single re-infection with Trichostrongylus colubriformis.
\end{abstract}

Keywords: antibody, gastrointestinal nematodes, serum, sheep, somatic antigen. Disciplinaria en Parasitología Veterinaria (CENID-PAVET), Instituto Nacional de Investigaciones Forestales Agrícolas y Pecuarias (INIFAP), Jiutepec, Morelos, México. ${ }^{3}$ División Académica de Ciencias Agropecuarias (DACA), Universidad Juárez Autónoma de Tabasco (UJAT), Villahermosa, Tabasco, México. CORRESPONDENCE: N.F. Ojeda-Robertos [nojedar@ hotmail.com - Tel.: +52 1993347 7588]. DACA - UJAT. Carretera Villahermosa-Teapa, km 25. CP 86280 Villahermosa, Tabasco, México. 


\section{INTRODUCTION}

Trichostrongylus colubriformis is one of the most prevalent gastrointestinal nematodes of sheep in warm climates $[7,15]$. In this nematode species, anthelmintic resistance (AR) has been reported [21]. The increase of AR in the Trichostrongylus genus and other species in many parts of the world [1,25] has motivated the search for alternative methods and control practices in order to achieve a sustainable use of anthelmintics $[18,26]$. One option is to increase the immune response level through the selection of animals with natural resistance [12]. In resistant breeds, such as Blackbelly [24] the lambs need to develop acquired immunity and avoid the major effects of parasitism that cause economic losses including mortality in lambs [5]. However, the successful selection of animals depends on the accurate assessment of the infection burden, immune response and production status. Considering those reasons, studies with antibody-mediated responses need to be undertaken [11] and for such reason is necessary to know the levels of some immunological indicators in sheep (eosinophils, $\operatorname{IgA}, \operatorname{IgG}, \operatorname{IgE}$ and IgM) which go along with the assessment of fecal nematode egg counts (FEC) to use the information in breeding programs $[2,8]$. One important measure is the IgA level in mucus [10]; but it is not easily measured in live animals [19] and detecting $\operatorname{IgA}$ in other fluids would be a potentially valuable tool in diagnosis. The aim of the study was to investigate the response of $\operatorname{IgA}$ and $\mathrm{IgG}$ in serum and saliva and the level of leukocyte cells involved in the acquired resistance in Blackbelly lambs after single artificial re-infection with a resistant strain of Trichostrongylus colubriformis.

\section{MATERIALS AND METHODS}

\section{Location}

The study was carried out in one sheep farm located in Salto de Agua, Chiapas, Mexico (17 $34^{\prime}$ $\mathrm{N}$ and $\left.92^{\circ} 29^{\prime} \mathrm{W}\right)$ at 85 meters above sea level. The climate of the region is a tropical rainforest [13]. It is classified as hot and humid with rainfall throughout the year. The average annual temperature is $26.6^{\circ} \mathrm{C}$ and the rainfall is $3289 \mathrm{~mm}$.

\section{Animal management}

Sixteen weaned lambs, of $15.7 \pm 3.0 \mathrm{~kg}$, infected with gastrointestinal nematodes were selected from one flock grazing in Brachiaria humidicola pad- docks during one month. The lambs were sampled to analyze the studied variables in their first infection. Then, all the lambs were treated with Albendazole ${ }^{1}$ (Valbazen $10 \% \mathrm{Co}, 10 \mathrm{mg} \mathrm{kg}^{-1}$ body weight, BW) and Levamisole ${ }^{1}$ (Ripercol L-12\%, $7.5 \mathrm{mg} \mathrm{kg}^{-1} \mathrm{BW}$ ) and stabled during two months. After that, two groups were formed because in eight lambs, fecal reduction of nematode eggs was not obtained and anthelmintic resistance was observed in $T$. colubriformis by the identification of larvae in fecal cultures post treatment. These lambs remained naturally infected despite being treated (naturally infected with a resistant strain). Only the lambs with counts equal to zero EPG were re-infected with 6000 infective larvae of T. colubriformis (re-infected group). Another group of eight lambs born in elevated cages without infection served as negative control.

\section{Sample processing}

Jugular blood samples were taken into 5-mL vacutainers ${ }^{2}$. The blood plasma was stored at $-20^{\circ} \mathrm{C}$ for later antibody analysis. The percentage of the packed cell volume (\%, PCV) was determined by the microhematocrit method ${ }^{3}$. The plasmatic protein concentration was measured by refractometry ${ }^{4}$ and was expressed in $\mathrm{g} \mathrm{dL}^{-1}$. The absolute leukocytes were counted in a haemocytometer ${ }^{5}$ and reported in $\mathrm{L}$ of blood. Thin blood smears were prepared and stained with coloring kit $^{6}$ (Fast blood coloring).

Fecal samples were collected early in the morning, directly from the lamb rectum. The number of eggs per gram of feces was determined by the McMaster technique [6] with sensitivity of 50 eggs per gram.

In order to detect the total IgG and IgA antibodies in serum and saliva, an indirect ELISA ${ }^{7}$ was carried out with crude-extract antigen (Ag) from $T$. colubriformis adult worms [3]. The IgA salivary determination was performed according to the methodology described by Shaw et al. [23], except the Ag was not filtrated in Sephadex, and for such reason it was called hot water extract larval Ag (HWEL).

\section{Statistical analyses}

All the data were analyzed with one model of repeated measures in time by using the SAS statistical package [20] where the three treatments represented the fixed effects and the random effects were the animals:

$$
Y_{\mathrm{ijkl}}=\mu+\tau_{\mathrm{i}}+\rho_{\mathrm{j}}+\tau^{*} \rho_{\mathrm{ij}}+\delta_{\mathrm{k}}+\varepsilon_{\mathrm{ijk} \mathrm{l}}
$$


$Y_{i \mathrm{jkl}}=$ is the EPG, PCV, peripheral cell percentages, $\operatorname{IgA}$ and $\mathrm{IgG}$ optical density, $\mu=$ overall mean, $\tau_{\mathrm{i}}=$ the fixed effect of treatment, $\rho_{\mathrm{j}}=$ Effect of the sample day. $\tau^{*} \rho_{\mathrm{ij}}=$ interaction treatment and day, $\delta_{\mathrm{k}}=$ random effect of lamb, $\varepsilon_{\mathrm{ijk} k}=$ residual error.

\section{RESULTS}

During all the experiment, the FEC remained unchanged in the group naturally infected from grazing $(200 \pm 158 \mathrm{EPG}, P<0.01)$. Meanwhile, due to the effect of $T$. colubriformis re-infection, the FEC increased to $625 \pm 287 \mathrm{EPG}$ at 35 days post-infection (pi, $P<0.01$ ). The control lambs in elevated cages did not show infection (Figure 1).

The packed cell volume $(29.4 \pm 3.4 \%)$, basophil $(44 \pm 74)$, lymphocyte $(8443 \pm 2845)$ and monocyte $(77 \pm 91)$ counts $\left(\times 10^{6}\right.$ cell/L) were not affected by infection with $T$. colubriformis and no differences were observed among the three groups (Table 1). Nevertheless, neutrophils and total leukocytes were lower in the control group than in the re-infected and naturally infected lambs. The eosinophil counts increased in the re-infected lambs, while the naturally infected group and the control lambs were similar $(P<0.01)$.

The IgA determination in saliva with HWELAg showed differences among the groups in favor of the lambs infected with $T$. colubriformis. In addition, differences were observed in both groups, the naturally infected and in the control (Table 2).

The IgA levels in serum increased significantly after 15 days post-infection in the lambs re-infected with T. colubriformis $(\mathrm{OD}=1.69 \pm 0.5,80 \%$ with regards to standard). With the IgG it was not possible to distinguish the effect of infection with $T$. colubriformis between the re-infected and the naturally pre-infected lambs. Only the control lambs had low IgG activity (Figure 2).

Table 1. Hematologic response in lambs infected with Trichostrongylus colubriformis (reinfected group) compared with naturally infected and uninfected lambs.

\begin{tabular}{|c|c|c|c|c|c|c|}
\hline \multirow{2}{*}{ Variable } & \multicolumn{2}{|c|}{ Not infected } & \multicolumn{2}{|c|}{ Re-infected* } & \multicolumn{2}{|c|}{ Naturally infected $* *$} \\
\hline & Mean & Std Dev & Mean & Std Dev & Mean & Std Dev \\
\hline Number of lambs & 6 & & 6 & & 6 & \\
\hline $\operatorname{PCV}(\%)$ & $29.6^{\mathrm{a}}$ & 3.9 & $28.5^{\mathrm{a}}$ & 2.7 & $30.6^{\mathrm{a}}$ & 3.3 \\
\hline Plasmatic protein $(\mathrm{g} / \mathrm{dL})$ & $6.0^{\mathrm{b}}$ & 0.3 & $6.2^{\mathrm{a}}$ & 0.3 & $5.6^{\mathrm{c}}$ & 0.4 \\
\hline Leukocytes $\left(\times 10^{9}\right.$ cell/L) & $13.12^{\mathrm{b}}$ & 1.96 & $15.68^{\mathrm{a}}$ & 3.93 & $13.79^{\mathrm{ab}}$ & 5.26 \\
\hline Basophils (x106 cell/L) & $64^{\mathrm{a}}$ & 88 & $39^{a}$ & 66 & $29^{\mathrm{a}}$ & 55 \\
\hline Neutrophils (x109 cell/L) & $4.14^{\mathrm{b}}$ & 2.12 & $6.21^{\mathrm{a}}$ & 2.57 & $6.17^{\mathrm{a}}$ & 3.29 \\
\hline Eosinophils $\left(\times 10^{9}\right.$ cell/L) & $0.12^{\mathrm{b}}$ & 0.14 & $0.32^{\mathrm{a}}$ & 0.34 & $0.15^{\mathrm{b}}$ & 0.24 \\
\hline Monocytes (x106 cell/L) & $80^{\mathrm{a}}$ & 94 & $81^{\mathrm{a}}$ & 110 & $68^{\mathrm{a}}$ & 95 \\
\hline Lymphocytes $\left(\times 10^{9}\right.$ cell/L) & $8.72^{\mathrm{a}}$ & 2.36 & $9.02^{\mathrm{a}}$ & 3.37 & $7.37^{\mathrm{a}}$ & 2.58 \\
\hline
\end{tabular}

Table 2. Level of IgA with regards to standard in saliva in lambs infected with Trichostrongylus colubriformis (re-infected group) compared with naturally infected and uninfected lambs.

\begin{tabular}{cccccccc}
\hline & & \multicolumn{2}{c}{ Before grazing period d= -58 } & & \multicolumn{2}{c}{$\begin{array}{c}\text { After re-infection } \\
\text { d=34 dpi }\end{array}$} \\
\cline { 7 - 8 } \cline { 6 - 7 } Group & $\mathrm{N}$ & & Mean & SD & & Mean & SD \\
\hline Naturally infected & 6 & $3.2^{\mathrm{a}}$ & 0.96 & & $7.7^{\mathrm{b}}$ & 0.93 \\
Re-infected & 6 & & $3.8^{\mathrm{a}}$ & 0.42 & & $15.0^{\mathrm{c}}$ & 1.72 \\
Control lambs & 6 & & & & & $2.4^{\mathrm{a}}$ & 0.52 \\
\hline
\end{tabular}

$\mathrm{N}$ : Number of lambs. Different letter in the same column are statistically different $(P<0.01)$. 


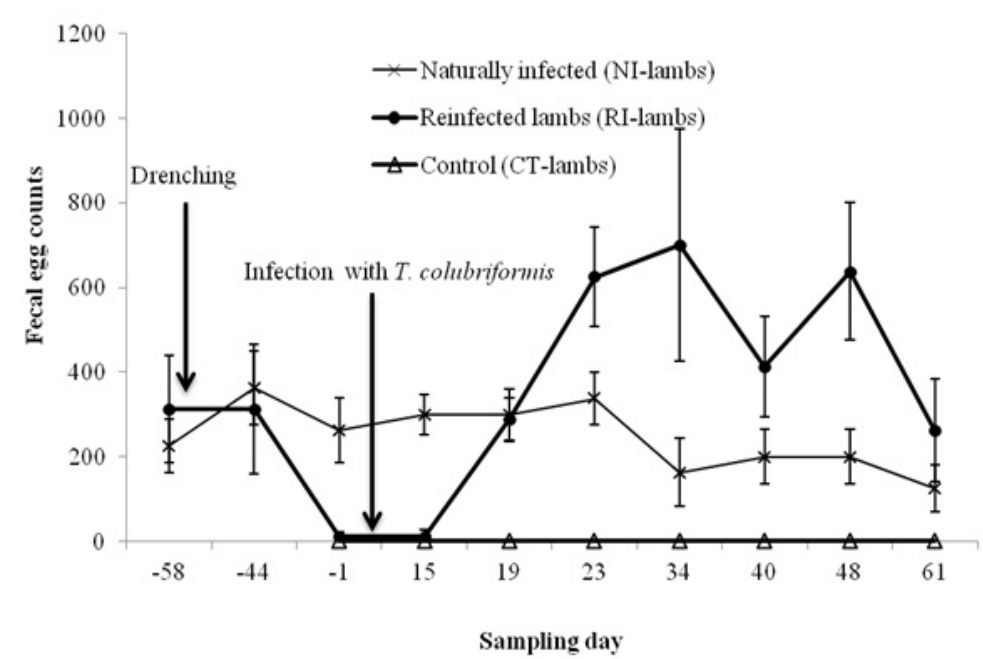

Figure 1. Fecal nematode egg counts in Blackbelly lambs infected with T. colubriformis. Mean \pm standard error.
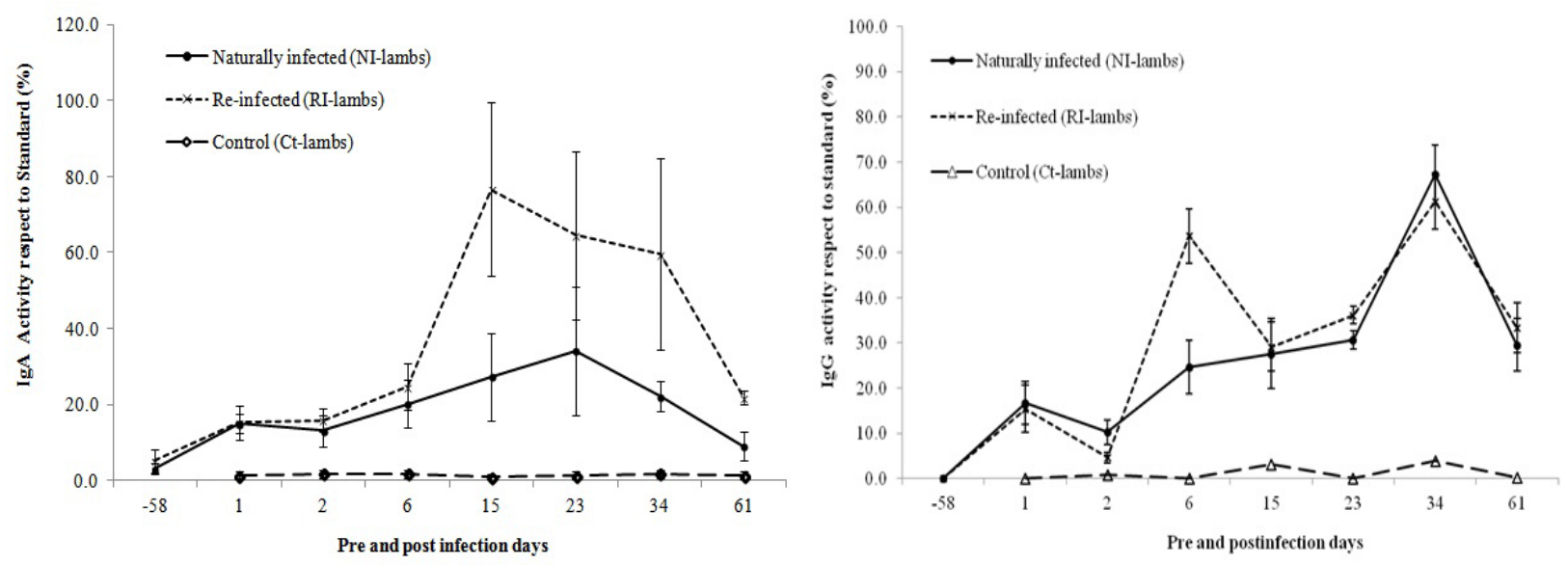

Figure 2. Serum IgA and IgG with regards to standard against worm crude Trichostrongylus colubriformis Ag in Blackbelly lambs.

\section{DISCUSSION}

Highly persistent infection of Trichostrongylus colubriformis was observed for at least four months in the naturally infected group despite having been treated with anthelmintics (Figure 1). It is a significant problem because this species has a high prevalence in the tropics of Mexico and specifically in the region of the study [14]. The problem increases when the anthelmintic resistance is the major issue, as in the case of this recently described flock [9]. For such reason, it is important to evaluate other alternatives in addition to chemical anthelmintic drugs, such as the ability of the animal to develop an immune response and reject the parasites on its own. The development of immunological response is therefore essential for understanding genetic resistance in the host. In another study, a natural reduction in the FEC was indicated at 100 days post-infection in the same species [22], but in the present work, the FEC could not be reduced until after about 120 days when the naturally infected lambs were evaluated.

The larger number of neutrophils and leukocytes in both the naturally infected and re-infected groups implies a sustained response for a long time. Neutrophils are destructive cells that arrive too early, help the organism to decide when to initiate and maintain an immune response, so after infection levels of neutrophils remain high [16]. While the higher counts of eosinophils only in the re-infected group were produced as an immediate response to infection with $T$. colubriformis, which is in agreement with another study [4]. Similarly, with a single infection of 
T. colubriformis, in Santa Ines sheep in Brazil, the infected lambs showed significantly higher levels of serum IgA than the control group [4]. However, they exhibited differences from the fifth to the $13^{\text {th }}$ week post-infection because it was the first infection. Meanwhile in another study [17] the peak of IgA in blood was reached at 10 days post-infection. This immediate response occurred in re-infected ewes with Teladorsagia circumcinta. The OD level decreased after day 10 pi to low levels in which the identification of the disease would not be possible [17]. In this case, differences in IgA activity were observed between the re-infected lambs and the other groups at fifteen days post-infection, because one sampling was conducted at this time, but the basal levels of IgA were higher in the naturally pre-infected lambs than the control group and were maintained at least for five weeks after infection.

IgA has been shown to be an important component of protective immunity. The increased level of IgA in serum and saliva with the re-infection with $T$. colubriformis was confirmed, as several studies have demonstrated, IgA plays a central role in the acquired immune response in the resistance against gastrointestinal nematode infections in sheep $[3,4,17]$. The increased production of $\operatorname{IgA}$ is an indicator of immune response to a gastrointestinal nematode infection.
This response has been associated with the activity of Th2 CD4+ lymphocytes and the increased number of inflammatory cells in the mucosa such as eosinophils, mast cells and globular leukocytes. Therefore, the elevated IgA levels observed may be more indicative of enhanced immunity in hair sheep [4].

In conclusion, an increase in the peripheral immune response in lambs with a single re-infection of $T$. colubriformis, resulted from the increase in $\operatorname{IgA}$ levels in serum and saliva, and increase in the number of peripheral eosinophils, total leukocytes and neutrophils. The re-infected lambs had a higher level of $\operatorname{IgA}$ than the naturally infected and control lambs, making it possible to improve the immune response with a single re-infection with Trichostrongylus colubriformis.

\section{MANUFACTURERS}

'Zoetis México. México D.F., Mexico.

${ }^{2}$ Becton Dickinson and Company. Franklin Lakes, NJ, USA.

${ }^{3}$ Nanjing Everich Medicare Import and Export Co. Shangai, China.

${ }^{4}$ Atago Co. Ltd. Tokio, Japan.

${ }^{5}$ Sigma-Aldrich Corporation. St. Louis, MO, USA.

${ }^{6}$ Hycel de Mexico S.A. de C.V. Jalisco, Mexico.

${ }^{7}$ Thermo Fischer Scientific Co. Ltd. Shangai, China.

Declaration of interest. The authors declare they have no conflicts of interest.

\section{REFERENCES}

1 Almeida F.A., Garcia K.C.O.D., Torgerson P.R. \& Amarante A.F.T. 2010. Multiple resistance to anthelmintics by Haemonchus contortus and Trichostrongylus colubriformis in sheep in Brazil. Parasitology International. 59: 622-625.

2 Bishop S.C. \& Morris C.A. 2007. Genetics of disease resistance in sheep and goats. Small Ruminant Research. 70 : 48-59.

3 Bowdridge S., MacKinnon K., McCann J.C., Zajac A.M. \& Notter D.R. 2013. Hair-type sheep generate an accelerated and longer-lived humoral immune response to Haemonchus contortus infection. Veterinary Parasitology. 196: 172-178.

4 Cardia D.F.F., Rocha-Oliveira R.A., Tsunemi M.H. \& Amarante A.F.T.D. 2011. Immune response and performance of growing Santa Ines lambs to artificial Trichostrongylus colubriformis infections. Veterinary Parasitology. 182: 248258.

5 Craig B.H., Pilkington J.G. \& Pemberton J.M. 2006. Gastrointestinal nematode species burdens and host mortality in a feral sheep population. Parasitology. 133: 485-496.

6 Cringoli G., Rinaldi L., Veneziano V., Capelli G. \& Scala A. 2004. The influence of flotation solution, sample dilution and the choice of McMaster slide area (volume) on the reliability of the McMaster technique in estimating the faecal egg counts of gastrointestinal strongyles and Dicrocoelium dendriticum in sheep. Veterinary Parasitology. 123: 121-131.

7 Cruz-Rojo M.A., Martínez-Valladares M. \& Rojo-Vázquez F.A. 2012. Teladorsagia circumcincta antibodies in serum and milk samples in experimentally infected lactating ewes. Veterinary Parasitology. 188: 386-390.

8 de la Chevrotière C., Bambou J.C., Arquet R., Jacquiet P. \& Mandonnet N. 2012. Genetic analysis of the potential role of IgA and IgE responses against Haemonchus contortus in parasite resistance of Creole goats. Veterinary Parasitology. 186: 337-343. 
9 González-Garduño R., López-Arellano M.E., Ojeda-Robertos N., Liébano-Hernández E. \& Mendoza-de Gives P. 2014. Diagnóstico in vitro y en campo de resistencia antihelmíntica en nematodos gastrointestinales de pequeños rumiantes. Archivos de Medicina Veterinaria. 46: 399-405.

10 Harrison G.B.L., Pulford H.D., Hein W.R., Barber T.K., Shaw R.J., McNeill M. \& Wakefield J. 2003. Immune rejection of Trichostrongylus colubriformis in sheep; a possible role for intestinal mucus antibody against an L3-specific surface Ag. Parasite Immunology. 25: 45-53.

11 Hunt P.W., Kijas J. \& Ingham A. 2013. Understanding parasitic infection in sheep to design more efficient animal selection strategies. The Veterinary Journal. 197: 143-152.

12 Kemper K.E., Palmer D.G., Liu S.M., Greeff J.C., Bishop S.C. \& Karlsson L.J.E. 2010. Reduction of faecal worm egg count, worm numbers and worm fecundity in sheep selected for worm resistance following artificial infection with Teladorsagia circumcincta and Trichostrongylus colubriformis. Veterinary Parasitology. 171: 238-246.

13 Kottek M., Grieser J., Beck C., Rudolf B. \& Rubel F. 2006. World Map of the Köppen-Geiger climate classification updated. Meteorologische Zeitschrift. 15: 259-263.

14 López-Ruvalcaba O.A., González-Garduño R., Osorio-Arce M.M., Aranda-Ibañez E. \& Díaz-Rivera P. 2013. Cargas y especies prevalentes de nematodos gastrointestinales en ovinos de pelo destinados al abasto. Revista Mexicana de Ciencia Pecuaria. 4: 223-234.

15 Macarthur F.A., Kahn L.P. \& Windon R.G. 2013. Immune response of twin-bearing Merino ewes when infected with Haemonchus contortus: Effects of fat score and prepartum supplementation. Livestock Science. 157: 568-576.

16 Mantovani A., Cassatella M.A., Costantini C. \& Jaillon S. 2011. Neutrophils in the activation and regulation of innate and adaptive immunity. Nature Reviews Immunology. 11: 519-531.

17 Martínez-Valladares M., Vara-Del Río M.P. \& Rojo-Vázquez F.A. 2007. Use of a $203 \alpha \alpha$ fragment of Tc-PDI to detect IgA activity during infection by Teladorsagiacircumcincta in sheep. Parasitology Research. 100: 1213-1220.

18 Patten T., Good B., Hanrahan J.P., Mulcahy G. \& de Waal T. 2011. Gastrointestinal nematode control practices on lowland sheep farms in Ireland with reference to selection for anthelmintic resistance. Irish Veterinary Journal. 64: 4. [doi:10.1186/2046-0481-64-4].

19 Prada J. de C.J. Matthews L., Mair C., Stefan T. \& Stear M.J. 2014. The transfer of IgA from mucus to plasma and the implications for diagnosis and control of nematode infections. Parasitology. 141: 875-879.

20 SAS Institute. 2004. SAS/STAT User's Guide, Version 9.2. Cary, NC. SAS Institute.

21 Scott I., Pomroy W.E., Kenyon P.R., Smith G., Adlington B. \& Moss A. 2013. Lack of efficacy of monepantel against Teladorsagia circumcincta and Trichostrongylus colubriformis. Veterinary Parasitology. 198: 166-171.

22 Shaw R.J., Gatehouse T.K. \& McNeill M.M. 1998. Serum IgE responses during primary and challenge infections of sheep with Trichostrongylus colubriformis. International Journal of Parasitology. 28: 293-302.

23 Shaw R.J., Morris C.A., Wheeler M., Tate M. \& Sutherland I.A. 2012. Salivary IgA: a suitable measure of immunity to gastrointestinal nematodes in sheep. Veterinary Parasitology. 186: 109-117.

24 Terefe G., Lacroux C., Andréoletti O., Grisez C., Prevot F., Bergeaud J.P., Penicaud J., Rouillon V., Gruner L., Brunel J., Francois D., Bouix J., Dorchies P. \& Jacquiet P. 2007. Immune response to Haemonchus contortus infection in susceptible (INRA 401) and resistant (Barbados Black Belly) breeds of lambs. Parasite Immunology. 29: 415-424.

25 Waghorn T.S., Knight J.S. \& Leathwick D.M. 2014. The distribution and anthelmintic resistance status of Trichostrongylus colubriformis, T. vitrinus and T. axei in lambs in New Zealand. New Zealand Veterinary Journal. 62: 152-159.

26 Williams A.R., Palmer D.G., Williams I.H., Vercoe P.E. \& Karlsson L.J.E. 2010. Faecal dry matter, inflammatory cells and antibodies in parasite-resistant sheep challenged with either Trichostrongylus colubriformis or Teladorsagia circumcincta. Veterinary Parasitology. 170: 230-237.

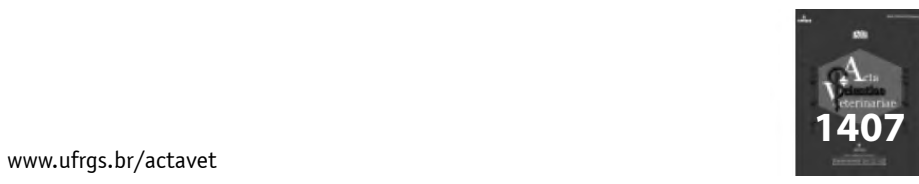

